\title{
Urgences
}

\section{Tendres flashes (dessin d'Elisabeth Savard)}

\section{Alain Blanchet}

Numéro 7, 2e trimestre 1983

URI : https://id.erudit.org/iderudit/025100ar

DOI : https://doi.org/10.7202/025100ar

Aller au sommaire du numéro

Éditeur(s)

Urgences

ISSN

0226-9554 (imprimé)

1927-3924 (numérique)

Découvrir la revue

Citer ce document

Blanchet, A. (1983). Tendres flashes (dessin d'Elisabeth Savard). Urgences, (7),

7-12. https://doi.org/10.7202/025100ar

Ce document est protégé par la loi sur le droit d'auteur. L’utilisation des services d'Érudit (y compris la reproduction) est assujettie à sa politique d'utilisation que vous pouvez consulter en ligne.

https://apropos.erudit.org/fr/usagers/politique-dutilisation/
Cet article est diffusé et préservé par Érudit.

Érudit est un consortium interuniversitaire sans but lucratif composé de l’Université de Montréal, l’Université Laval et l’Université du Québec à Montréal. Il a pour mission la promotion et la valorisation de la recherche. https://www.erudit.org/fr/ 


\section{ALAIN BLANCHET}

\section{Tendres flashes}

(dessin de Elizabeth Savard) 
Tu sais. aucun fait ne t'échappe. il n'y a pas de pente à remonter ni à redescendre. tous ces déplacements comme des transferts de magie pure entre nous ne sont pas perdus. si le moteur peut bien continuer à tourner. s'il y a de l'eau au moulin.

il y a de l'eau au moulin.

De ma fenêtre j'entrevois le faîte d'un érable qui commence à jaunir. un signe d'automne. tout ce temps j'ai chaviré dans ta barque en essayant de vider l'eau avec une petite cannette rouillée. tes jambes magnifiques aux frontières de mon corps. mes mains massant tes épaules. tu me manques à en crever. et je pense que c'est à mon tour de crever. car je n'ai pas l'intention de retourner si près de toi. pas dans les mêmes conditions. je me suis assez fait mal. tu es en train de calfeutrer tes ouvertures pour I'hiver. je t'ai dans la peau.

Aucun fait ne t'échappe. mais ton interprétation est sujette à modification. nous avons fait un bon bout de chemin ensemble. ça me laisse sur ma faim. je saisis dans mon délire l'espèce de danse effrénée et apaisante qui pourrait nous emporter de nouveau.

après cette solitude.

après cette déchirure.

II n'est pas question de tâter le terrain. ni de se forger des réactions d'amants blessés. des allures de précipices infranchissables. assis chacun à notre table. déployant notre énergie à tour de bras et la sentant se perdre dans la boucane. il y a beaucoup de femmes et d'hommes qui rampent sous la loi et qui en sont les esclaves. tu vis au-dessus de cette loi. je vis au-dessus de cette loi. je l'affirme sans prétention. je suis sûr de ceci lorsque ça s'applique à nous. et je suis certain que ça s'applique à d'autres. you must be honest to live outside the law.

Ne t'enferme pas à double tour. j'ai su pas mal de bonne heure qu'on en viendrait à ce silence. et je ne suis pas un changeur de destinée. pour toute cette lumière qui t'inonde au clair de lune. ou en plein soleil d'après-midi. nue et fragile. pour ces danses sous les étoiles et pour ces voyages en tapis volants. pour ces élans chargés de satisfaction et de paix. pour ce café noir et ce 
sandwich mérités un lundi de septembre au café Sainte-Julie de la rue des Zouaves. pour ces réveils à tes côtés. dans la prunelle de tes yeux avec ton odeur matinale. pour ces pas sous la pluie et ces longues distances d'une cabine téléphonique. pour cette reconnaissance et cette vérité qui se meut en toi. pour tout cela il faut se préparer. sous ce ciel troué. sur terre. à s'élancer à la folie dans un champ en pleine croissance.

où nul sentier ne paraît pour nous servir de guide.

Ce qui s'est passé ces jours derniers a permis d'éteindre les tisons d'un feu qui s'achevait déjà depuis un temps. il reste des cendres. il reste à faire un ménage et à jeter cette cendre dans le jardin. pour que le cycle se perpétue avec nos respirs en contre gigue.

Ce matin j'écris ces mots sous les premiers chants des oiseaux. bien avant que les femmes et les hommes se lèvent pour faire leur ouvrage.

please don't pass me by. 
Cherchant une tanière pour me reposer j'ai abouti dans le creux d'une vague mystérieuse entre les crans je me suis raidi entre tes jambes malgré l'oppression étouffante

I'odeur de la grosse bière mêlée aux cris et aux murmures des frères et soeurs qui mélangent les couleurs dans leurs cerveaux baignés d'ombre de lune avec du miel sur leurs chevilles

et j'ai senti si bien l'air frais de ton corps habité par une hallucination tranquille étoilée pour mieux révéler toute la réalité de ton souffle et de ton sang qui coule dans mes veines qui coule dans nos veines en dessous de tes bijoux qui ne sont que froid et beauté

et tu bouges bien ta salive en réaction avec ta centrale électrique en cascades d'une force inouie où chutent toutes les langues et toutes les caresses en une rivière à fleur de peau comme une rébellion totale dans l'espace et le temps

nous sommes baignés d'ombre de lune avec du miel sur les chevilles 


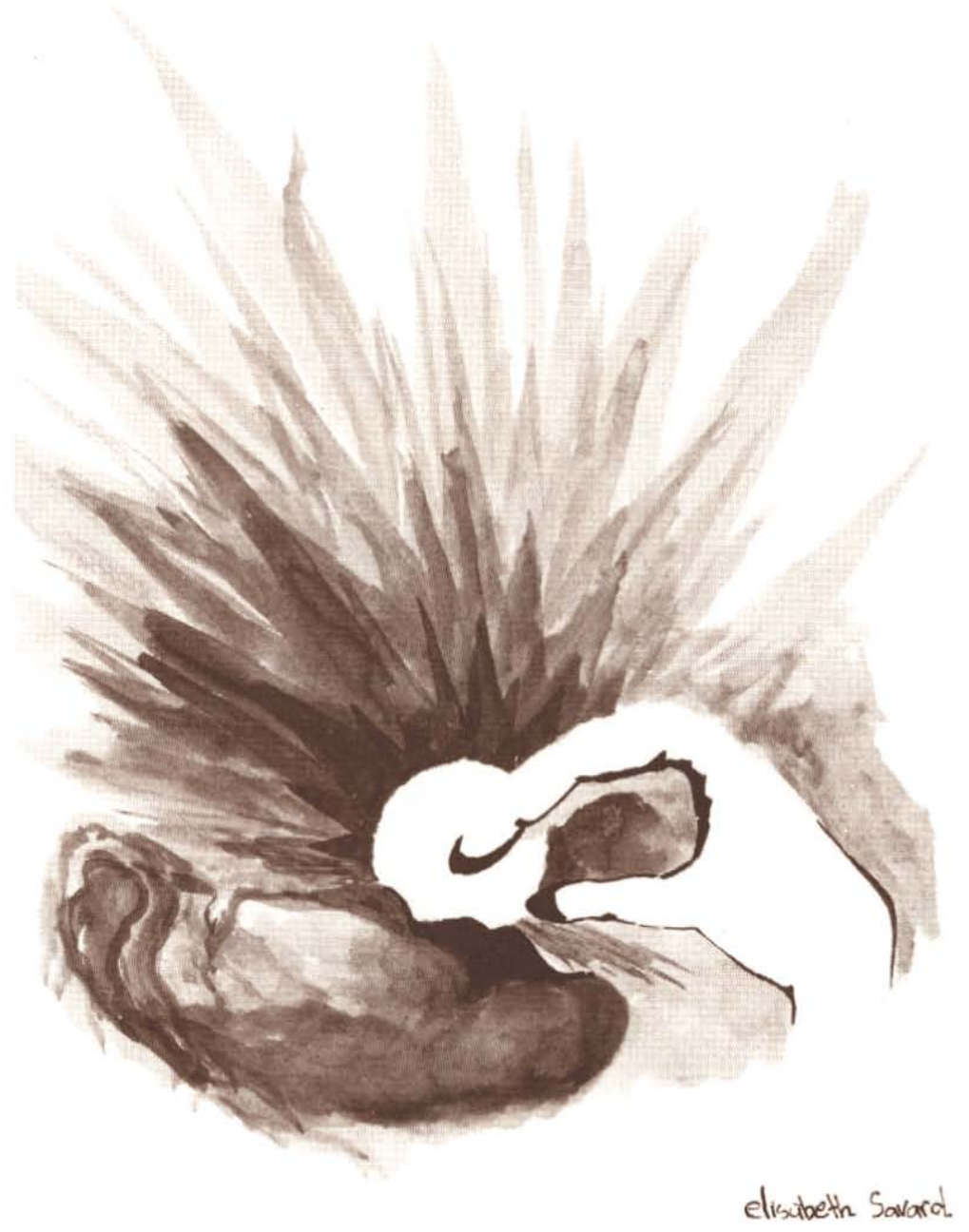


Infinité de spasmes

et de retenue

envol de cheveux. langues torturées

long cheminement de ma main sur ton dos

ta sueur de brume. mon cri de tempête

je bois ton eau pure sous la lueur de chandelle

pieds qui s'épousent. danses de feu

senteurs féroces et souffles confondus

mouvement superbe. les mains dans le virage des fesses

montée. vertige. ivresse. descente

ta robustesse dans ma franchise. puis nos dents

puis nos sourires et nos murmures

le temps que ça prend pour se refaire la respiration

le sperme sur le drap. les oreillers moites

ces frémissements à chaque frôlement de cuisses

se sentir aimés et désirés et perdus et abandonnés

envoûtés par notre amour même fou braque

dans nos rythmes et dans nos élans

mais être bien et jouir de nous par-dessus tout

comme le gibier insaisissable que nous sommes

heureux dans des sentiers inconnus

à I'ombre et au soleil

amants d'arcs-en-ciel. amis cruels

en attente et en impatience

se sentir pénétrés et caressés et mangés et bus et mordillés

se sentir comme vent et feuille

concients des images projetées par nos corps

enlacés dans les vitrines de la rue

se bercer la vue et se bercer les sens

et s'endormir nus

émergence de la lave

soudain le volcan. soudain l'éteinte

le thé au citron et l'éclat de tes yeux de femme ma bouche glissant sur la pointe de tes seins errante 